\title{
A INVISIBILIDADE DA FILOSOFIA AFRICANA NO DISCURSO ACADÊMICO BRASILEIRO
}

\section{The invisibility of african philosophy in the brazilian academic discourse}

\section{L'invisibilité de la philosophie africaine dans le discours académique brésilien}

\section{Luis Thiago Freire Dantas*}

Resumo: O objetivo deste artigo é questionar a invisibilidade da filosofia africana no discurso acadêmico brasileiro. Para isso, o artigo refletirá sobre a ideologia que é a causa da compreensão da falta de história no continente africano, em seguida o artigo apresentará a complexidade que há em atribuir uma identidade africana, assim como criticar a noção de Etnofilosofia através do filósofo camaronês Marcien Towa. Finalmente, o artigo considerará tal invisibilidade como efeito de uma reprodução colonizadora que, para se desenvolver, necessita de legitimação europeia do próprio discurso.

Palavras-chave: Colonização. Filosofia africana. Racismo.

\begin{abstract}
The purpose of this article is to question the invisibility of African philosophy in academic discourse. For this, the article will reflect on the ideology that is the cause of this lack of understanding of the history on the African continent, and then the article will present the complexity of assigning an African identity, but also to criticize the concept of ethnophilosophy by philosopher Cameroon Marcien Towa. Finally, the article considers this invisibility as a colonizer read effect to develop, require very European legitimizing expression.
\end{abstract}

Keywords: African philosophy. Colonization. Racism.

* Mestre em Filosofia pela Universidade Federal do Paraná (UFPR). Doutorando em Filosofia: História da Filosofia pela (UFPR).E-mail: fdthiago@gmail.com 
Résumé: Le objectif cet article est en questionner l'invisibilité de la philosophie africaine dans le discours académique. Pour ça, l'article refléchirá sur l'idéologie qui est la cause de ce manque de compréhension de l'histoire sur le continent africain, puis l'article présentera la complexité d'assigner une identité africaine, mais aussi de critiquer la notion de Etnofilosofia par le philosophe camerounais Marcien Towa. Enfin, l'article considère cette invisibilité comme un effet de lecture colonisatrice que pour développer, nécessite de légitimation européenne d'expression propre.

Mots-clés: Colonisation. Philosophie africain. Racisme.

\section{Introdução}

Um curso de filosofia tem em suas diferentes disciplinas uma série de filósofos que são cruciais para a formação discente, por exemplo, Platão, Aristóteles, Descartes, Kant, Hegel, Heidegger e alguns outros. A partir dessa gama de autores, decorre uma construção de ideia de filosofia que a caracteriza como uma formulação de pensamento em larga medida europeia que, em consequência, legitima a melhor maneira de escrever e analisar um texto filosófico. A partir disso, alguns aspectos são recorrentes e por mais que diferenças surjam nos autores, há um princípio comum que é reproduzido quase de maneira espontânea: os conceitos filosóficos têm sua origem grega. Isso pode ser observado nos conceitos: política, ética, técnica e natureza que são originados, respectivamente, das palavras gregas: pólis, ethos, techné, physis. $\mathrm{Na}$ compreensão dessa origem implica-se que o fazer filosófico apenas tem validade se há um diálogo com a tradição grega que, coincidentemente, na elaboração de aulas se recorre também fundamentar um conceito filosófico em um filósofo alemão, francês ou inglês, isto é, em um europeu. Por conseguinte, argumenta-se sobre o fazer filosófico como uma expressão grega e europeia, e a definição de uma filosofia ocidental-europeia seria uma tautologia:

A palavra philosophia diz-nos que a filosofia é algo que pela primeira vez e antes de tudo vinca a existência do mundo grego. Não só isto - a philosophia determina também a linha mestra de nossa história ocidental-europeia. A batida expressão 'filosofia ocidental-europeia' 
é, na verdade, uma tautologia. Por quê? Porque a 'filosofia' é grega em sua essência, e grego aqui significa: a filosofia é nas origens de sua essência de tal natureza que ela primeiro se apoderou do mundo grego e só dele, usando-o para se desenvolver (HEIDEGGER, 1979, p. 212, grifos do autor).

Essa passagem tenta justificar o motivo da filosofia ser greco-europeia, de tal modo que o estranhamento em expressar uma filosofia fora desse lugar, por exemplo, uma filosofia africana, surge àquele pesquisador ou pesquisadora que corrobora com a ideia de filosofia enquanto uma produção europeia. Assim, a impossibilidade de indicar a existência de uma filosofia africana não impede somente de pensar uma filosofia que tenha suas raízes nesse continente, ou seja, que há um modo de interpretar os conceitos diferentes do europeu, mas na medida em que a filosofia é uma atividade humana, dizer que há certos humanos que não filosofam é defini-los como privados da própria humanidade. Dessa forma, Ramose argumenta o seguinte:

Afirmamos que não há nenhuma base ontológica para negar a existência de uma filosofia africana. Também argumentamos que, frequentemente, a luta pela definição de filosofia é, em última análise, o esforço para adquirir poder epistemológico e político sobre os outros (RAMOSE, 2011, p. 14).

Diante dessa situação é que se pretende nesse artigo expor de que maneira a invisibilidade da filosofia africana manifesta-se no discurso acadêmico brasileiro. Principalmente, porque se entende que problematizar a invisibilidade não diz respeito à produção de uma filosofia nacional, mas no fundo, está em jogo o modo afro-brasileiro de pensar, que permite construir princípios e possibilidades para os acontecimentos próximos a nossa própria história. Com isso, o artigo iniciará explicando como a discriminação aos africanos possui um discurso na filosofia europeia de modo que na importância de um filósofo, por exemplo, Heidegger, para a filosofia contemporânea, contém nessa filosofia um questionamento e afirmação sobre a ausência de humanidade a certo grupo humano: os cafres. Para contrapor tal racialismo, o artigo descreverá dois temas da filosofia africana, a problematização da identidade de uma filosofia africana e a crítica à etnofilosofia. 
A partir de tais reflexões, o artigo apontará para alguns aspectos que caracterizam a invisibilidade do pensamento africano no discurso acadêmico brasileiro. Enfocando em uma das características sobre a ideia de que a filosofia no Brasil necessita de subserviência a um modelo e a sua reprodução ainda continua por meio de comentários e não de uma filosofia com aspectos brasileiros.

\section{2 - Heidegger e os cafres: a normatividade da história}

Martin Heidegger foi um filósofo alemão do século XX de enorme influência em vários pensadores e em diferentes áreas das ciências humanas. Tal influência foi motivada em grande parte pelas teses apresentadas no livro Ser e tempo (2012) que tem como eixo principal a pergunta: qual o sentido do ser? Tal questionamento mostrava-se necessário para Heidegger porque a palavra ser na tradição filosófica caiu em uma série de pré-conceitos: i) universalidade, isto é, o ser consiste no conceito mais universal de todos podendo apresentar-se em diferentes modos; ii) indefinibilidade, que decorrente da universalidade o ser não teria uma definição fixa, podendo dessa forma ser definido, ou não, de maneiras diversas; iii) evidência, ou seja, fazemos uso do conceito de ser e o compreendemos sem necessitar de uma investigação precisa sobre o conceito (HEIDEGGER, 2012, p. 35-39). E precisamente por causa dessa ausência de investigação que Heidegger estabelece o questionamento sobre o sentido do ser como principal tema em Ser e Tempo e, por consequência, radica esse livro como um clássico filosófico:

Para compreendermos a importância de Ser e Tempo na história da Filosofia e, ainda, a consciência que Heidegger tinha dessa importância, poderíamos usar, sem temor, a palavra ecumenismo [...]. Todos os grandes autores foram convocados para um reexame da questão do ser, a começar por Platão. É assim que o ecumenismo heideggeriano revela independência em relação a respostas de autores clássicos, mas, ao mesmo tempo, os convida, mediante uma reinterpretação, para um novo modo de pensar a questão do sentido do ser (STEIN, 2011, p. 47). 
Com essa proposta, como cita alguns comentadores (STEIN, 2011), a importância desse livro já era enorme antes mesmo de ser publicado e com sua publicação apenas confirmou o autor como um dos maiores pensadores do século XX. A singularidade das teses heideggerianas em grande parte consolidou-se devido muitos interlocutores enfocarem mais no aspecto existencial de um ente, que Heidegger privilegiou na sua investigação, o Dasein. Esse enfoque decorre pelo fato de que o Dasein afirma o ser humano como um ente situado, primordialmente, no mundo. Partindo dessa condição originária, a constituição de pessoa, de indivíduo, de ser social ou de sujeito seria subsequente ao Dasein:

Segundo Heidegger, é preciso mostrar que o ser do Dasein é totalmente diferente daquele dos outros entes. Se a constituição do Dasein é completamente distinta da constituição dos outros entes, então é possível encontrar nele mesmo o acontecer transcendental (STEIN, 2011, p. 65).

Além disso, uma das características desse ente é que ele é um ser histórico, ou seja, "o Dasein tem cada vez sua 'história' e pode tê-la porque o ser desse ente é constituído pela historicidade" (HEIDEGGER, 2012, p. 1035), pois “'O Dasein 'é' seu passado no modo do seu ser, o qual, para dizer rudemente, 'se gesta' (geschiet) cada vez a partir de seu futuro" (HEIDEGGER, 2012, p. 81, grifos do autor).

Diante desse caráter inovador presente em sua obra, a filiação de Heidegger ao partido nacional-socialista de Hitler em 1933 e, na mesma época assumindo um cargo de reitor na universidade de Freiburg, não impediu de que sua filosofia tivesse uma enorme influência em diversas teorias ${ }^{1}$. Porém, nesse período conturbado, uma preleção importante para esse artigo diz

1 "Nos anos 1930 encontramos Sartre trabalhando O ser e o nada sob o impacto direto de Ser e tempo. Jean Beaufret foi o elo e o intérprete principal de Heidegger depois da segunda Guerra, na França. E, desde então, a presença da Filosofia heideggeriana tornouse tão forte naquele país que foi por meio dela que se retornou a Husserl. A. Camus, G. Marcel, M. M.-Ponty são autores que trabalharam sob a influência de Heidegger. Filósofos pós-modernos, como M. Foucault, J. Derrida, J.-F. Lyotard, G. Vattimo e P. Sloterdijk recorrem a Heidegger, sobretudo na sua crítica à subjetividade e ao iluminismo" (STEIN, 2011, p. 42). 
respeito à primeira ministrada por Heidegger após a renúncia ao reitorado em 1934: Lógica - a pergunta pela essência da linguagem. Essa preleção tinha outro título: $O$ estado e a ciência, mas Heidegger a reformulou com intuito de apresentar a Lógica não como uma propedêutica na formulação de juízos, e sim como questionadora da própria linguagem. Diante disso, Heidegger expôs que a construção de um povo a partir de teses biológicas não consistiria em um caráter real de um povo, pois este se forma por meio da linguagem. Contudo, mesmo com essa advertência Heidegger não escapou de expressar um tipo de racismo, no sentido de avaliar um grupo humanidade a partir de uma ausência normativa, no caso, a história:

nomeadamente que a história é aquilo que distingue o ser dos humanos. Por outro lado, poder-se-ia objetar que há humanos e grupos humanos (negros, como por exemplo, os cafres) que não têm história, dos quais nós dizemos que são a-históricos. Mas, por outro lado, a vida da fauna e da flora tem uma história de milhares de anos e cheia de peripécias. Os fósseis dão um testemunho instrutivo acerca disso. Não apenas a vida, sob a qual nós compreendemos os animais e as plantas, mas também toda a terra tem a sua história [...] Por conseguinte, há história também fora do âmbito do homem, por outro lado ela pode faltar no seio do âmbito humano, como entre os negros. Com isso, a história não seria nenhuma determinação distintiva do ser humano (HEIDEGGER, 2008, p. 141, grifos nossos).

Antes de analisar as implicações dessa passagem, é fortuito explicar quem seriam os cafres. Primeiramente, o termo "cafre" foi usado historicamente em correspondência aos povos nativos da África austral, contudo tal palavra foi adquirindo conotações racistas e ofensivas durante o período colonial (principalmente na África do Sul) e, originalmente, cafres seriam aqueles povos africanos não-muçulmanos o que os indicariam como infiéis. Nesse caminho, utilizar essa palavra não corresponde a uma ignorância de Heidegger frente ao seu significado, mas somente intensifica o propósito do autor em avaliar quem, ou o quê, possuiria a designação de histórico. O mais impactante é que os estudiosos da filoso- 
fia heideggeriana não cita essa passagem, exceto em momentos breves ${ }^{2}$. Facilmente entende-se que essa ausência de incômodo é consequência de uma consciência geral que a África é um país que não possui capacidade de abstração e é permeada por um senso não-crítico, além do que as populações africanas estariam em um estágio anterior a civilização, como se lê na Filosofia da história de Hegel:

A África não é parte histórica do mundo. Não têm movimentos, progressos a mostrar, movimentos históricos próprios dela. Quer isso dizer que a sua parte setentrional pertence ao mundo europeu ou asiático. Aquilo que entendemos precisamente pela África é o espírito a-histórico, o espírito não desenvolvido, ainda envolto em condições de natural e que deve ser aqui apresentado apenas como no limiar da história do mundo (HEGEL, 2001, p. 111).

Apesar de tal afirmação hegeliana aproximar da passagem destacada na preleção de Heidegger, em compensação, muitos comentadores indicam a impossibilidade de deduzir do pensamento heideggeriano qualquer argumento favorável a teorias eugenistas, porque "o Dasein não possui aqui nenhuma corporeidade originária e não pode consequentemente ser pensado a partir de algum primado genético específico" (CASANOVA, 2009, p. 151). Porém, na leitura destacada sobre os cafres, apreende-se que há uma exclusão propiciada pelo elemento histórico que Bernasconi (2010, p. 61, grifos nossos) adverte: “esta maneira de pensar sobre 'o povo' diferencia Heidegger de alguns dos teóricos biologicamente raciais do seu tempo, mas não há nada de inocente sobre o julgamento que apenas os povos históricos são verdadeiramente um povo".

Por isso, para um melhor entendimento dessa problemática, é necessário investigar a descrição que Heidegger apresenta sobre os dois modos da história

2 Essa passagem intriga ainda mais porque grande parte dos leitores e comentadores da obra do Heidegger não atentou suficientemente para implicações dessa passagem. Tanto que em um levantamento bibliográfico sobre a citação dos cafres como grupos humanos ausente de história, foi encontrada apenas em Bernasconi (2010), Sonia Sikka (2003), Osongo-Lokadi (2006) e Faye (2012). Porém, vale destacar o trabalho de Osongo-Lokadi: Heidegger et l'afrique: reception et paradoxe d'un dialogue monologique, que realiza uma análise da compreensão heideggeriana acerca dos africanos. 
manifestar-se: a história natural e a história como ingresso no futuro. O primeiro tipo diz respeito a um suceder do tempo em que os fatos são assinalados para que entrem no passado e "aí é indiferente em que domínio de fatos esta sucessão ocorre" (HEIDEGGER, 2008b, p. 142). Com isso, vale destacar que para interpretar a história como natural, o autor interroga se as plantas ou animais contêm uma história e na resposta acerca da história às plantas ou aos animais, Heidegger indica a pertença do povo cafre à história natural, isto pelo fato de eles estarem próximos dos animais: "contudo, eles [os cafres] têm tanta história quanto os macacos e os pássaros" (HEIDEGGER, 2008b, p. 143) e, em consequência, afirmar que "mas nem toda e qualquer coisa que passa e pertence ao passado entrará na história" (HEIDEGGER, 2008b, p. 143).

Contudo, de acordo com Heidegger, a possibilidade de um povo a-histórico entrar na história só é passível de ocorrer quando isso corresponder a um ingresso não no passado, mas no futuro (este seria o segundo tipo dos dois modos em que a história pode se manifestar). $\mathrm{O}$ interessante é que essa possibilidade, ao que parece, ocorre por meio da eliminação da história (futuro): "um povo entra na história (passado), na medida em que ele é eliminado da história (futuro)" (HEIDEGGER, 2008b, p. 144). Assim, se a entrada na história, no caso exemplificado os cafres, deve-se pela eliminação da história (futuro), então é provável dizer que qualquer povo ausente de proximidade aparente com o "nós" só tem a eliminação como possibilidade para entrar em uma história. Dessa maneira, parte das problematizações de Heidegger sobre a história como elemento distintivo do humano tem relação com a instauração de um povo em conformidade a um de seus conceitos capitais: o acontecimento apropriativo (Ereignis), pois em contraste com aquela caracterizada pelo natural, a história como ingresso no futuro escapa de um encadeamento factual dos entes no mundo. Assim, "os povos não entram na história como se ela fosse um espaço pronto no qual encontram refúgio, [...] mas 'fazer história' significa: criar primeiro o espaço e o solo" (HEIDEGGER, 2008b, p. 145, grifos do autor).

Perante essas observações, como se pode acompanhar, por mais que Heidegger tenha uma apresentação de que o não-histórico só é possível àqueles entes que têm na sua constituição o histórico (no caso, o humano), ainda há uma diferenciação de povos de maneira que os sem história são incluídos pela exclusão. E pelo fato de que a exclusão ainda permanece centrada como uma única perspectiva de compreender os povos a-históricos, ela permite que se discuta essa constituição de um povo histórico a partir 
do racismo. Porque, por mais que a questão sobre a raça seja tratada por Heidegger na preleção Lógica, no intuito de afastar a formação de povo a partir da ideia de corpo, para Bernasconi o tratamento da ideia de raça em Heidegger deve-se ao fato de que "o racismo e a filosofia ocidental estavam tão intimamente ligados que levou [a Heidegger] pensar diverso sobre o que até então havia chamado de "raça"' (BERNASCONI, 2010, p. 49).

Esse pensar diverso pode ser encontrado na preleção Lógica em que para questionar a definição de povo como corpo (Volk as Leib), Heidegger realiza um jogo semântico entre as palavras Rassisch e Rassige: "Racial no primeiro sentido não necessita de ser, de modo algum, de raça nobre e pode, antes pelo contrário, ser inteiramente destituído de raça" (HEIDEGGER, 2008, p. 121). Com isso, Franco de Sá (2009, p. 519) comenta que nesse ponto "Heidegger alude aqui a impossibilidade de determinar a essência do homem pela biologia ou pelo modo de ser da vida" e em consequência recusa que raça no termo biológico "tenha, por si só, a possibilidade de conferir algum valor, alguma qualidade relevante ou merecimento" (SÁ, 2009, p. 519). Em contrapartida, Maldonado-Torres (2008) argumenta que o afastamento heideggeriano do racismo biológico do nazi-fascismo não o distancia de outra forma de racismo: o epistêmico. Este está relacionado com a política e a sociedade, que o autor assim define: "O racismo epistêmico descura a capacidade epistêmica de certos grupos de pessoas. Pode basear-se na metafísica ou na ontologia, mas o resultado acaba por ser o mesmo: evitar reconhecer os outros como seres inteiramente humanos" (MALDONADO-TORRES, 2008, p. 79).

Assim, ao formular uma justificativa que determina os cafres como aquele grupo humano ausente de história, Heidegger não distancia da tradição europeia que reproduz(iu) a ideia de que no continente africano há uma humanidade ainda a ser construída. E através disso, há uma falta de atenção à produção filosófica africana. Por isso, antes de explicar como tal ideologia ainda é presente no discurso filosófico brasileiro por meio da invisibilidade, este artigo pretende explicar a importância da filosofia africana para o pensamento humano e depois apresentar que esta é construída por princípios racionais capaz de dialogar com a europeia.

\section{3 - Como se poderá reconhecer a importância da filosofia africana?}

A dificuldade em refletir sobre a filosofia africana é primeiramente pelo 
questionamento se há uma filosofia africana. Com certeza não há da mesma maneira que não há uma filosofia europeia, ou seja, uma uniformidade de pensamento no interior de um continente. Mas a pergunta pela existência de tal filosofia consiste em problematizar dois pontos: i) localizar geograficamente uma filosofia sugere-se um saber não restrito a um sistema ou a uma metodologia, mas está em sintonia com a própria formação de povos; ii) atribuir ao continente africano uma filosofia é afirmar uma história construída por si mesmo e em diálogo com outras filosofias.

O primeiro ponto aproxima-se do questionamento sobre uma identidade africana, que é teorizada por diversos pensadores, pela exigência de afirmar-se diante dos outros:

É verdade, é claro, que a identidade africana ainda está em processo de formação. Não há uma identidade final que seja africana. Mas, ao mesmo tempo, existe uma identidade nascente. E ela tem certo contexto e certo sentido. Porque, quando alguém me encontra, digamos, numa loja de Cambridge, ele indaga: 'Você é da África?' O que significa que a África representa alguma coisa para algumas pessoas. Cada um desses rótulos tem um sentido, um preço e uma responsabilidade (ACHEBE apud APPIAH, 2010, p. 241, grifo do autor).

Tal significado tem como resultado precisamente a invisibilidade que o africano tem no mundo, mas como pode ser invisibilidade se há uma visibilidade? Precisamente porque o que está visível, numa análise mais nítida, não é o africano em sua própria constituição, e sim a forma como o outro os vê e julga como eles devem ser. Isto significa que a identidade africana é, principalmente para uma sociedade eurocêntrica, reduzida a um estereótipo que contribui para o esclarecimento daquela sociedade e nunca da africana. Esse "paradoxo" é um processo de racismo epistêmico em que se movimenta através de uma legitimação identitária e retira a possibilidade reconhecer a produção "não-ocidental" de conhecimento:

[O racismo epistêmico] opera privilegiando as políticas identitárias (identity politics) dos brancos ocidentais, ou seja, a tradição de pensamento e pensadores dos homens ocidentais (que quase nunca inclui as mulheres) é considerada como a única legítima para a pro- 
dução de conhecimentos e como a única com capacidade de acesso à 'universidade' e à 'verdade'. O racismo epistêmico considera os conhecimentos não-ocidentais como inferiores aos conhecimentos ocidentais (GROSFOGUEL, 2007, p. 32).

Entretanto, a identidade africana deve ser compreendida não por um modelo correspondente a uma união, mas que reconheça na diversidade e na multiplicidade a constituição da identidade, uma vez que conforme explica Appiah (2010):

Se identidade é uma coalescência de estilos de conduta, hábitos de pensamento e padrões de avaliação mutuamente correspondentes (ainda que às vezes conflitantes), em suma, um tipo coerente de psicologia social humana - equivaleria a 'dar a um nada etéreo um local de habitação e um nome’ (APPIAH, 2010, p. 243).

Da questão da identidade surge o segundo ponto: a atribuição de uma filosofia africana. Inicialmente, é necessário elucidar que ela não se manifestou somente contemporaneamente, mas contém consigo uma história que se inicia, até onde se sabe, com o Egito Antigo. A partir disso, produz-se uma tensão por interrogar sobre a própria origem da filosofia, porque há um debate no intuito de apresentar uma origem não grega de tal saber, já que houve uma contribuição egípcia e com o destaque inclusive para o fenótipo negro desta sociedade: "Atribuir falsamente à Grécia os valores de um Egito supostamente branco revela uma profunda contradição, que não é a menos importante prova da origem negra do Egito" (DIOP, 1974, p. 234). Atento a essa discussão, esse artigo problematiza que discursar a filosofia, enquanto não centrada em uma discussão europeia, propiciaria uma reflexão da filosofia extrapolando uma produção localizada, isto é, uma Geofilosofia. ${ }^{3}$ Tanto mais pelo fato de que entende-se a filosofia como global e nessa "globalização" acarreta uma pluri-versalidade que tem como origem um diálogo entre Europa, África e povos do Oriente.

3 Deleuze e Guattari (2010) executam uma tese que a filosofia possui desenvolvimento não por um caráter histórico dos gregos, mas pela localização geográfica que permitiu a sua elaboração, assim como, posteriormente encontrou o campo necessário para sua permanência na Inglaterra, França e Alemanha. Diante dessa consideração ocorre o surgimento de uma Geofilosofia. 
Para ilustrar esse debate, segue-se uma passagem escrita por Theophile Obenga (2004), em que descreve a tarefa da filosofia futura no mundo:

É mero preconceito acreditar que a época filosófica da humanidade comece primeiro entre os gregos no quinto século A.C. Este preconceito implica que outro povo antigo não empreende um pensamento especulativo. (...) O espírito da filosofia Chinesa, filosofia Indiana, filosofia Africana, filosofia Europeia, e filosofia Maia pode diferir enormemente em seu tratamento do assunto, mas filosofia sempre se trata do conhecimento humano, e da elevação da mente. A filosofia futura do mundo deve tomar o cerne relato a grande sistema especulativo de toda humanidade (OBENGA, 2004, p. 31).

Desse modo, a filosofia não está no seu fim, antes com essas atuais discussões questiona-se a geopolítica filosófica, na perspectiva de trazer os conceitos formados a partir da contextualização em que o pensamento atua, enfocando nos meios em que um povo reflete sobre princípios do mundo e, assim, constrói uma série de argumentos explicando o motivo de algo consistir de uma determinada forma e não de outra.

Porém, essa atitude não condiciona em um saber popular, na verdade, inúmeros filósofos africanos contrapõem a sugestão de a filosofia africana ser um etnofilosofia, isto é, uma produção de conceitos permeados pelas máximas populares e invariavelmente situa-se dentro de uma hierarquia que os africanos fazem uma "filosofia popular", enquanto $a$ filosofia permanece sendo grega e com desenvolvimento na Europa. Diante desses aspectos, o próximo tópico tratará da crítica de Marcien Towa à etnofilosofia.

\section{4 - Marcien Towa: a filosofia africana não é uma etnofilosofia}

Se há um momento em que a África teve uma aparente nascença ao universo europeu, com certeza diz respeito à pesquisa etnográfica do missionário belga Placide Temples. Este reuniu as observações feitas ao grupo étnico banto e a partir disso escreveu o que seria denominado como Filosofia Banto. Apesar da contribuição realizada pelo missionário, esse estudo etnográfico situou tal filosofia ainda como ausente de protagonismo, isto é, a 
filosofia Banto ainda era permeada de noções populares e religiosas afastada de uma construção de princípios tal qual a filosofia tradicional é construída. Com isso, definiu-se a filosofia banto como etnofilosofia.

O problema da etnofilosofia é que a sua legitimidade tornou possível não por meio do povo pertencente ao continente africano, mas necessitou da vinda de um europeu para poder apresentar a sua importância. Desse modo, a crítica, por exemplo, do beninense Paul Hountondji (2010) é que por meio da etnofilosofia reforçava a ideia de que os africanos não compreendia que todo o pensamento ancestral seria uma filosofia: "normalmente, os autores partiam do princípio de que os africanos não tinham consciência da sua própria filosofia e que apenas os analistas ocidentais (...) poderiam traçar um quadro sistemático da sua sabedoria" (HOUNTONDJI, 2010, p. 133).

Outro crítico à etnofilosofia consiste no filósofo camaronês Marcien Towa (2009). Towa elabora teses filosóficas que tem a proposta de construir uma identidade à filosofia africana de maneira que esta não seja menor em relação à europeia, mas que tenha um diálogo forte $\mathrm{e}$ contenha outras perspectivas a questões tradicionais. Por isso, ao referir-se à etnofilosofia, Towa explica que "ela residiu de fato em abraçar indiscriminadamente a civilização ocidental, de tomá-la totalmente como superior a nossa" (TOWA, 2009, p. 39). Quando o sentido principal para Towa em realizar uma filosofia africana seria: "nosso propósito principal deverá ser de alcançar uma crise e uma expressão filosófica de nosso 'ser-no-mundo' atual e uma determinação da forma de apoio e de refletir uma direção definida" (TOWA, 2009, p. 35).

"Crise e expressão filosófica" correspondem, dessa maneira, a uma forma de posicionar a própria identidade diante das subjugações que o continente africano sofreu com a colonização europeia. Principalmente através da ideologia que consolida a Europa enquanto engenho da história com o seu ápice na filosofia hegeliana:

O imperialismo ocidental trouxe uma de suas expressões ideológicas mais elaboradas na filosofia hegeliana da história, segundo a qual, a civilização moderna da Europa constitui a síntese universal de todos os valores produzidos para humanidade em curso de sua longa história (TOWA, 2011, p. 338). 
Assim, a importância da reflexão africana está em sintonia com os críticos da colonização que a Etnofilosofia não realiza, apesar da intenção de recuperar a "antropologia própria" e a dignidade humana dos africanos (TOWA, 2009). Entre os críticos está o martiniquense Aimé Césaire que formulou o conceito originário de negritude que, para Towa, continha o propósito de reclamar o direito fundamental de independência política, ou seja, "o direito de iniciativa histórica". Contudo, a dificuldade estaria no fato de que "Esse direito roubado pelo colonizador deve ser oficialmente reconhecido por este último" (TOWA, 2009, p. 36), no interior dessa reflexão, Césaire produz um pensar voltado para a condição do colonizado de maneira que tenta convencê-lo da possibilidade de libertação por meio da luta e quanto ao colonizador resta persuadi-lo para realizar a descolonização.

Todavia, a dificuldade da descolonização diz respeito à legitimação do método filosófico, de tal modo que Towa levanta uma objeção a partir de uma diferença de conceitos entre o que seria o modelo europeu e o que seria o africano. Primeiramente, é preciso ter em mente que o fazer filosófico não consisti num jogo etimológico de palavras, mas uma consideração sobre o mundo em seus princípios e, por consequência, refletir acerca do absoluto: "Filosofia existe. Apresenta-se como umas coleções de obras que se dizem filosóficas. A leitura dessas obras impõe a ideia de que a filosofia é a coragem de pensar o absoluto" (TOWA, 2012, p. 17). E, assim considera como tarefa do filosofar africano contemporâneo:

A história de nosso pensar não deve se propor a exumação de uma filosofia que nos dispensariam de filosofar, mas acima de tudo a determinação do que em nós é subversivo para que seja possível a subversão do mundo e da nossa atual condição no mundo (TOWA, 2009, p. 75).

Precisamente pela subversão é que consiste na maneira de como o pensamento guia-se na perspectiva cosmopolita. Um tipo de subversão diz respeito à origem da filosofia, pois como escrito anteriormente sobre $\mathrm{o}$ questionamento da influencia egípcia à filosofia grega, Towa acompanha a crítica sobre a noção de "milagre grego", por ressaltar o Egito antigo como a irmã mais velha da Grécia antiga e esta tendo em muitos aspectos 
reprodução de princípios já alicerçados entre os pensadores egípcios. Com isso, apresentar a filosofia como um discurso muito antes nômade em que as construções teóricas seriam efeitos de uma troca de saberes entre diversos pensadores em suas culturas é decorrente de que o Egito por muito tempo fora tratado pelos pensadores gregos como um estágio para desenvolver suas ideias, por exemplo, é documentado que Pitágoras passou 20 anos no Egito, Demócrito 5 anos e Platão 13 anos.

Outro aspecto situa-se na passagem do mito à filosofia, de acordo com Towa esse afastamento entre mito e filosofia é aparente na medida em que um e outro estão interligados impossibilitando uma autonomia na correlação entre ambos. Principalmente porque a produção de uma filosofia não possui uma distância maior do mito se questionar acerca da condição instintiva aos humanos. Por isso, Towa escreve que "O homo philosophicus tem menos direito sobre o homo mythicus que ele sobre o animal, porque a lacuna é menos profunda entre a filosofia e o mito do que entre o mito e o instinto" (TOWA, 2009, p. 13).

Levando em conta que o importante dessas considerações não é invalidar uma filosofia, mas questionar sobre o modo de ser filosófico, então se procura não restringir a filosofia em uma disciplina acadêmica, antes ter em mente que se trata de um projeto político em que ser filósofo é dar ao pensamento um espaço de atuação no mundo. Com isso, o mundo não se refere a uma totalidade que viria revelar um discurso harmônico e/ou universal, mas antes que o mundo seria uma série de fragmentos em que o múltiplo se funde no pensar.

\section{5 - O caminho para uma filosofia afro-brasileira}

Depois de apresentar alguns aspectos que formaram a ideia de África e como alguns filósofos africanos contradizem tal idealização. Agora se problematizará o caráter da invisibilidade da filosofia africana no Brasil por meio dos discursos acadêmicos que ainda permanecem centrados em uma perspectiva europeia.

Com isso, um dos aspectos da invisibilidade pertence a uma produção acadêmica reprodutora de uma linguagem eurocêntrica que não problematiza a própria condição. Isso se aproxima do que Frantz Fanon (2008) define enquanto ser-colonizado, ou seja, uma condição de subordinação em que o 
colonizado procura afastar-se da própria cultura com a intenção de aproximar-se da pertencente ao colono, ou nas palavras de Fanon, da metrópole:

Todo povo colonizado - isto é, todo povo no seio do qual nasceu um complexo de inferioridade devido ao sepultamento de sua originalidade cultural - toma posição diante da linguagem da nação civilizadora, isto é, da cultura metropolitana (FANON, 2008, p. 34).

Um bom exemplo de tal colonização diz respeito a seguinte advertência de Miguel Reale (1961) para a formação de uma filosofia brasileira:

Integrados que estamos nas coordenadas da civilização do Ocidente, como filhos da prodigiosa cultura europeia, dela só podemos nos emancipar como se emancipam os filhos dignos, dignificando e potenciando a herança paterna, cientes e conscientes da nobreza de nossa estirpe espiritual. Não ignoro as contribuições das culturas ameríndia e africana na modelagem da que justamente se considera a maior 'democracia racial' do planeta, mas tais influências, mau grado a pretensão de certos 'africanistas', não são de molde a afastar-nos das linhas mestras do pensamento oriundo das fontes greco-latinas (REALE, 1961, p. 117).

Assim, conforme descreve o autor, a presença da filosofia brasileira necessita de uma valorização das fontes greco-latinas e, posteriormente, destacar as influências europeias no exercício do filosofar. E seguindo esse posicionamento ocorre o afastamento das possibilidades mais próprias da cultura brasileira, tudo com o sentido de tornar-se europeu. Essa transformação seria algo também destacado por Fanon enquanto busca de reconhecimento daquele carregado de negritude para com os da branquidade:

O negro quer ser como o branco. Para o negro não há senão um destino. E ele é branco. Já faz muito tempo que o negro admitiu a superioridade indiscutível do branco e todos os seus esforços tendem a realizar uma existência branca (FANON, 2008, p. 188).

Desse modo, a produção de uma filosofia que escape totalmente do modelo europeu seria muito antes uma construção não sistemática de sabe- 
res populares, por consequência, se a filosofia brasileira ainda não é capaz de fazer uma filosofia, então resta fazer comentários acerca da europeia:

Certamente, não podemos esquecer o papel da missão francesa na Universidade de São Paulo, o trabalho de Gerard Lebrun, que ocupou a cadeira de Gilles Gaston Granger, o fato de que Foucault estava no Brasil (e não apenas São Paulo), quando escreveu As palavras e as coisas, e que ele entrou em debate com o mesmo Lebrun. Embora hoje em dia, a filosofia brasileira é menos amplamente voltada para a Europa, fica-se impressionado com a presença e importância de figuras notáveis na filosofia contemporânea europeia, alemã, francesa e italiana, em particular, Hannah Arendt, Jürgen Habermas, Gilles Deleuze, Foucault, Toni Negri, Giorgio Agamben, etc... Seria um grande interesse em compreender os 'usos brasileiros' desses autores, à luz das questões atuais. Nossa preocupação ao propor esta questão é bem mais modesta (FIGUEIREDO; KIFFER; PUJOL, 2012, p. 1-2).

Assim, a "especificidade" da filosofia brasileira consistiria em uma apropriação de pensadores europeus, entretanto, apropriação que indicaria ainda uma exaltação de um modo de fazer filosofia e impede uma reflexão precisa sobre a história do pensamento brasileiro. Contudo, diante dessa especificidade, exercitar uma filosofia brasileira estaria dentro da proposta desse artigo em tratar o europeu somente como mais um interlocutor, não um normatizador. Para isso, entende-se que o importante seria trabalhar a ancestralidade, já que a possibilidade de construir uma filosofia brasileira invariavelmente circula-se com a entrada da ancestralidade como movimento para criar um pensamento que não necessite de uma legitimidade outrem, mas os próprios pensadores que afirmam o estatuto filosófico de seus textos. Tal posicionamento aproximaria do que Hountodji explica como filosofia africana: "Eu falo de filosofia africana como um conjunto de textos: conjunto, precisamente, de textos escritos por africanos e qualificados pelos próprios autores de filosóficos" (HOUTONDJI, 2013, p. 3, grifos do autor).

Além do que, a discussão da ancestralidade no âmbito filosófico seria não somente transformá-la em conceito, mas inclusive em agir eticamente com o nosso contexto: 
Aqui, Ancestralidade é, então, mais que um conceito ou categoria do pensamento. Ela se traduz numa experiência de forma cultural que, por ser experiência, é já uma ética, uma vez que confere sentido às atitudes que se desdobram de seu útero cósmico até tornarem-se criaturas nascidas no ventre terra deste continente metafórico que produziu sua experiência histórica, e desse continente histórico que produziu suas metonímias em territórios de além-mar, sem duplicar, mas mantendo uma relação trans-histórica e trans-simbólica com os territórios para onde a sorte espalhou seus filhos. Para além do conceito de ancestralidade, ela tornou-se uma categoria capaz de dialogar com a experiência africana em solo brasileiro (OLIVEIRA, 2012, p. 40).

Portanto, a partir da exposição realizada nesse artigo, tornar visível a filosofia africana no discurso acadêmico brasileiro não se limita a uma maneira de interromper a produção de um pensamento para privilegiar outro, mas, ao contrário, pensar com a filosofia africana é repensar a condição de colonizado por meio de propor uma autonomia capaz de refletir e dialogar sem necessariamente cair em uma reprodução de saberes.

\section{Referências}

APPIAH, Kwame Anthony. Na casa do meu pai: A África na filosofia da Cultura. São Paulo: Contraponto, 2010.

CASANOVA, Marco Antonio. Compreender Heidegger. Rio de Janeiro: Vozes, 2009.

DIOP, Cheikh-Anta. The African origin of civilization: myth or reality. Westport: Lawrence Hill, 1974.

FANON, Frantz. Pele negra, máscaras brancas. Salvador: EDUFBA, 2008.

FAYE, Emmanuel. Ser, história e extermínio na obra de Heidegger. Educação e Filosofia, Uberlândia, v. 26, n. 52, p. 613-640, jul./dez. 2012.

FIGUEIREDO, Vinícius; KIFFER, Ana; PUJOL, Stéphane. Comment peut-on être philosophe...au Brésil? Rue Descartes, Paris, v. 4, n. 76, p. 1-6. 2012. 
GROSFOGUEL, Ramón. Dilemas dos estudos étnicos norte-americanos: multiculturalismo identitário, colonização disciplinar e epistemologias descoloniais. Ciência e Cultura, São Paulo, v. 59, n. 2, p. 32-35, June, 2007.

HEGEL, Friedrich. The philosophy of history. Ontario: Kitchener, 2001.

HOUTONDJI, Paul. Conhecimento de África, conhecimentos de africanos: duas perspectivas sobre os estudos africanos. In: SANTOS, Boaventura; MENESES, Maria Paula. Epistemologias do Sul. São Paulo: Cortez, 2010, p. 131-144.

- Sur la philosophy africaine: critique de l'ethnophilosophy. Mankon: Langaa RPCIG, 2013.

HEIDEGGER, Martin. O que é isto: a filosofia? In: . Os pensadores: conferências e escritos filosóficos. São Paulo: Abril Cultural, 1979.

HEIDEGGER, Martin. Lógica: a pergunta pela essência da linguagem. Tradução de Helga Hidock Quadrado e Maria Adelaide PACHECO. Lisboa: Calouste Gulbekian, 2008.

2012.

. Ser e tempo. Campinas: Unicamp; Petrópolis: Editora Vozes,

MALDONADO-TORRES, Nelson. Topologia do ser e a geopolítica do conhecimento: modernidade, império e colonialidade. In: SANTOS, Boaventura de Sousa; MENEZES, Maria Paula. Epistemologia do Sul. Coimbra: Almedina, 2009, p. 337-382.

OSONGO-LUKADI, Antoin. Heidegger et l'afrique: reception et paradoxe d'un dialogue monologique. Paris: L'Hartmann, 2006.

OBENGA, Theophile. Egypt: ancient history of african philosophy. In: WIREDU, Kwasi. A companion to African philosophy. Massachustes: Blackwell Publish, 2004.

OLIVEIRA, Eduardo David de. Filosofia da ancestralidade como filosofia africana: educação e cultura afro-brasileira. Revista Sul-Americana de Filosofia e Educação, Brasília, n. 18, p. 28-47, maio/out. 2012.

REALE, Miguel. A filosofia como autoconsciência de um povo. Revista da Faculdade de Filosofia do Direito. São Paulo: Edusp, 1961, p. 104-125. 
SIKKA, Sônia. Heidegger anda Race. In: BERNASCONI, Robert. Race and racism in continental philosophy. Indiana: Indiana University Press, 2003.

STEIN, Ernildo. Pensar e errar: um ajuste com Heidegger. Rio Grande do Sul: Unijuí, 2011.

TOWA, Marcien. Essai sur le problematique philosophique dans l'Afrique actual. Yaoundé: Editions Clé, 2009.

. The idea of a negro-african philosophy. In: . Marcien

Towa's african philosophy: Two Texts. Hdri Publishers, 2012.

Data de registro: $12 / 03 / 2013$

Data de aceite: $1 \% / 12 / 2015$ 